\title{
IMPLEMENTASI PERATURAN DAERAH NOMOR 3 TAHUN 2014 TENTANG KAWASAN TANPA ROKOK (KTR) DI KANTOR SATUAN POLISI PAMONG PRAJA KOTA PALANGKA RAYA
}

\author{
Implementation Of Local Regulation Number 3 Of 2014 About No Smoking Area At Satuan Polisi \\ Pamong Praja Palangka Raya Office
}

\author{
Suprayitno ${ }^{1 *}$ \\ Widyakanti2* \\ Sidderatul Akbar ${ }^{3 *}$
}

Email:

suprayitno@fisip.upr.ac.id

\author{
*IUniversitas Palangka \\ Raya ,Indonesia
}

*3,4Universitas Lambung

Mangkurat, Indonesia

\begin{abstract}
Abstrak
Salah satu fungsi utama Satpol PP Kota Palangka Raya adalah menegakkan peraturan daerah dan menjadi barometer implementasi peraturan daerah khususnya peraturan daerah no.3 Tahun 2014 Tentang Kawasan Tanpa Rokok (KTR) di Kota Palangka Raya. Tetapi ternyata masih banyak Personel yang merokok di Kantor Satpol PP Kota Palangka Raya sehingga hal ini menarik untuk diteliti.

Penelitian ini dilakukan di Kantor Satpol PP Kota Palangka Raya dengan menggunakan metode kualitatif deskriptif. Hasil Penelitian ini menunjukan implementasi Perda Kawasan Tanpa Rokok di Satpol PP Kota Palangka Raya belum terimplementasi dengan baik. Hal ini karena belum adanya Sosialisasi menyeluruh, Sistem Pengawasan yang masih lemah, Belum adanya Penegakan dan Pembinaan yang optimal kepada personel. Sumber data dalam penelitian ini adalah data primer berupa hasil observasi dan wawancara serta pendukung data lainnya. Teknik pengumpulan datanya adalah observasi, wawancara, dokumentasi. Teknik analisis data nya adalah reduksi data, penyajian data, penarikan kesimpulan dan verifikasi data

Satpol PP Kota Palangka Raya sebagai garda terdepan penegakan peraturan daerah harus menjadi contoh bahwa mereka mampu mengimplementasikan peraturan tersebut di internal mereka. Harus ada perbaikan di internal Satpol PP Kota Palangka Raya agar Perda no.3 Tahun 2014 Tentang Kawasan Tanpa Rokok (KTR) dapat terimplementasi dengan baik dengan cara Melakukan Sosialisasi Menyeluruh, Memberikan Sanksi Yang Tegas, Harus Ada SOP yang Jelas, Penambahan Kamera Pengawas, dan Melarang aktivitas jual beli rokok di Kantor Satpol PP Kota Palangka Raya.
\end{abstract}

\begin{abstract}
One of the main functions of Palangkaraya Satpol PP Officers (Civil Service Police Unit) is enforcing the local regulations and becoming a barometer of the local regulation implementation especially No. 3 of 2014 about No Smoking Area in Palangkaraya City. But there are many personnel members who still smoke at Palangkaraya Satpol PP Office, so it is interesting to study.

This research was conducted at the Palangkaraya Satpol PP office using descriptive qualitative method. The results of this study showed that the implementation of Local Regulation about No Smoking Area at Palangkaraya Satpol PP office has not been well implemented. This is because there is no a comprehensive socialization, The monitoring system is still weak. There is no an optimal enforcement and fostering to all personnel members. Data sources in this research are the primary data on observations and interviews also public society as well as supporting other data. Data collection techniques are observation, interview and documentation. The data analysis techniques are data reduction, data presentation, drawing conclusion and data verification.
\end{abstract}

Palangkaraya Satpol PP officers as the frontline enforcement of local regulations should show that they are able to implement this regulation themselves. There should be improvement on Palangkaraya Satpol PP personnel members so that the Local Regulations No. 3 of 2014 about No Smoking Area can be well implemented by means of conducting comprehensive socialization, giving assertive penalties, there must be also a clear standard operating procedure, adding surveillance cameras, and prohibiting cigarettes trading activity at Palangkaraya Satpol PP Office.
Accepted

September 2020

Published

December 2020 


\section{METODOLOGI}

Penelitian ini menggunakan pendekatan metodologi Kualitatif Deskriptif. Penelitian ini akan menggali, menggambarkan dan menganalisa secara deskriptif berbagai fenomena, faktor dan realitas yang di temui dilapangan, untuk diketahui, digambarkan dan dianalisa terkait Implementasi Peraturan Daerah Nomor 3 Tahun 2014 Tentang Kawasan Tanpa Rokok di Satpol PP Kota Palangka Raya.

\section{HASIL DAN PEMBAHASAN}

\section{Kebijakan Publik}

Menurut William N. Dunn dalam pasolong (2008:39), mengatakan bahwa kebijakan publik adalah suatu rangkaian pilihan-pilihan yang saling berhubungan yang dibuat oleh lembaga atau pejabat pemerintah pada bidang-bidang yang menyangkut tugas pemerintahan, seperti pertahanan keamanan, energy, kesehatan, pendidikan, kesejahteraan masyarakat, kriminalitas, perkotaan dan lain-lain. Menurut Dye dalam Pasolong (2008:39) mengatakan bahwa kebijakan publik adalah "apapun yang pilih pemerintah untuk dilakukan atau tidak dilakukan". Jenis - Jenis landasan Kebijakan Publik Menurut Hirarkinya dalam Undang - Undang Nomor 12 Tahun 2011 : Undang - Undang Dasar Negara Republik Indonesia Tahun 1945, Ketetapan Majelis Permusyawaratan Rakyat (MPR), Undang - Undang / Peraturan Pemerintah Pengganti Undang - Undang, Peraturan Pemerintah, Peraturan Presiden, Peraturan Daerah Provinsi dan Peraturan Daerah Kabupaten/Kota

Dye dalam Widodo (2007:16-17) proses kebijakan publik meliputi beberapa hal yaitu : Identifikasi masalah kebijakan, Penyusunan agenda, Perumusan kebijakan, Pengesahan kebijakan, Implementasi Kebijakan, Evaluasi Kebijakan, Evaluasi kebijakan dilakukan oleh lembaga pemerintah sendiri, konsultan di luar pemerintah, pers, dan masyarakat.

Van Meter dan Van Horn dalam Agustino (2014:139) mendefinisikan implementasi kebijakan, merupakan tindakan yang dilakukan baik oleh individu atau pejabat-pejabat atau kelompok-kelompok pemerintah atau swasta yang diarahkan pada tercapainya tujuan - tujuan yang telah digariskan dalam keputusan kebijaksanaan.

George C. Edward III dalam Agustino (2014:150) mengungkapkan bahwa ada 4 faktor penting dalam keberhasilan implementasi kebijakan publik yaitu Komunikasi, Sumber Daya, Disposisi dan Struktur Birokrasi
Menurut Gow dan Marros dalam Pasolong (2008:59) di beberapa implementasi kebijakan terdapat berbagai hambatan antara lain : Kelemahan institusi, Ketidakmampuan SDM di bidang teknis dan administrative, Kekurangan dalam bantuan teknis, Kurangnya desentralisasi dan partisipasi, Pengaturan waktu, Sistem informasi yang kurang mendukung, Perbedaan tujuan antar actor, Hambatan Politik, Ekonomi dan Lingkungan dan Dukungan yang tidak berkesinambungan

Berdasarkan Perda Kota Palangka Raya Nomor 3 Tahun 2014 Secara umum yang termasuk Kawasan Tanpa Rokok meliputi : Fasilitas pelayanan kesehatan, Tempat proses belajar mengajar, Tempat anak bermain, Tempat ibadah, Fasilitas olahraga, Angkutan umum, Tempat kerja dan Tempat umum.

I. Implementasi Peraturan Daerah No.3 Tahun 2014 Tentang Kawasan Tanpa Rokok (KTR) di Kantor Satpol PP Kota Palangka Raya

a. Sosialisasi Perda No.3 Tahun 2014 di Internal Satpol PP Kota Palangka Raya

Terkait dengan adanya Sosialisasi Produk hukum dalam hal ini adalah Perda no.3 tahun 2014 Tentang Kawasan Tanpa Rokok (KTR) Seperti yang diungkapkan Oleh Kasat Pol PP Kota Palangka Raya, Baru I Sangkai yang Menyatakan bahwa :

"Beberapa bulan yang lalu pernah mengirimkan Personel Satpol PP Kota Palangka Raya untuk ikut Sosialiasi tentang Perda ini bersama dengan DPRD Kota Palangka Raya, Dinas Kesehatan dan Dinas terkait lainnya tentang Perda ini di Aula SMK 3 Palangka Raya " (Wawancara pada tanggal 18 Februari 2016).

Tahap Sosialisasi secara keseluruhan dari hasil wawancara yang didapatkan di atas menggambarkan bahwa sebenarnya di Internal Satpol PP Kota Palangka Raya tersebut telah ada Sosialisasi terkait Perda no.3 Tahun 2014 tersebut, tetapi hanya keterwakilan beberapa personel saja. Sedangkan personel lainnya yang tidak ikut sosialisasi tidak tahu dengan perda tersebut..

b. Pengawasan Bagi Para Personel Satpol PP Kota Palangka Raya Terkait Kawasan Tanpa Rokok (KTR)

Pengawasan / Controlling merupakan proses untuk mengamati secara terus menerus pelaksanaan kegiatan sesuai dengan rencana kerja yang sudah disusun dan mengadakan koreksi jika terjadi. Dalam Perda No.3 Tahun 2014 Terkait Pengawasan Kawasan Tanpa Rokok (KTR) disebutkan bahwa 
Kasat Pol PP melakukan pengawasan seluruh Kawasan Tanpa Rokok sebagaimana dimaksud dalam pasal 7 ayat 8 ( ada 8 Area Kawasan Tanpa Rokok).

Upaya yang telah dilakukan oleh Kasat Pol PP Kota Palangka Raya dan unsur pimpinan lainnya untuk meningkatkan pengawasan dan penyelenggaraan pemerintahan yang professional di Satpol PP seperti beberapa hasil wawancara diatas adalah dengan mengefektifkan pengawasan internal salah satunya adalah membentuk Petugas Tindak Internal (PTI).

\section{c. Penegakan Peraturan Daerah no.3 tahun 2014 Tentang Kawasan Tanpa Rokok di Satpol PP Kota Palangka Raya.}

Penegakan Peraturan Daerah No.3 Tahun 2014 Terkait Kawasan Tanpa Rokok (KTR) khususnya di Kantor Satpol PP Kota Palangka Raya sepertinya tidak ditegakkan dengan benar. Hal ini seperti yang diungkapkan oleh Bapak Reanson Gantar, $\mathrm{SH}$ Selalu Kasi Pembinaan, Pengawasan dan Penyuluhan yang mengatakan bahwa:

"Di kantor ini memang banyak yang merokok,tapi kita menunggu kesadaran anggota terutama yang merokok untuk sadar diri bahwa kantor ini adalah milik bersama. Sejauh ini kita belum memberikan sanksi karena kita belum ada masalah itu. Kita masih dalam tahap sosialisasi saja”. (wawancara pada tanggal 29 Februari 2016).

Dalam menegakkan sebuah peraturan ada tiga hal yang harus diperhatikan, yaitu kepastian hukum, kemanfaatan dan keadilan. Perda Nomor 3 Tahun 2014 Sebagai salah satu landasan hukum maka sudah menjadi kewajiban seluruh elemen masyarakat di Kota Palangka Raya termasuk anggota Satpol PP Kota Palangka Raya untuk tunduk dan patuh dengan Perda tersebut.

\section{d. Pembinaan bagi Anggota Satpol PP Kota Palangka Raya terkait Kawasan Tanpa Rokok (KTR).}

Salah Satu hal yang terpenting dari Penegakan Sebuah Peraturan adalah memberikan Pembinaan bagi pelanggar peraturan maupun pembinaan bagi siapapun agar tidak melanggar peraturan tersebut. Terkait pemberlakuan Kawasan Tanpa Rokok (KTR) di Kota Palangka Raya yang dilakukan oleh Unsur Pimpinan Satpol PP adalah selalu memberikan arahan dan wejangan bagi unsur pimpinan dan semua staf. Hal tersebut dilakukan ketika melakukan Apel Pagi dan Apel Sore.

2. Faktor Penghambat Implementasi Perda Nomor 3 Tahun 2014 di Kantor Satpol PP Kota Palangka Raya.

I. Adanya Pembiaran dan Kurangnya Komunikasi Antara Pimpinan Dan Bawahan.

Indikator bahwa kurangnya komunikasi dan adanya pembiaran terkait pemberlakuan perda Kawasan Tanpa (KTR) tersebut dapat disimpulkan dari tidak adanya teguran maupun saran dari unsur pimpinan yang membiarkan oknum - oknum Satpol PP merokok sebebas - bebasnya di Kantor tersebut.

\section{Kurangnya Sosialisasi}

Dari beberapa Informan yang didapatkan selama kegiatan penelitian, ternyata beberapa personel Satpol PP Kota Palangka Raya tidak mengetahui adanya pemberlakuan perda No.3 Tahun 2014 tentang Kawasan Tanpa Rokok (KTR)..

3. Kurangnya Sarana dan Prasarana Kamera Pengawas di Satpol PP Kota Palangka Raya

Kelengkapan akan Sarana dan

Prasarana tentunya menjadi faktor yang menentukan berhasil atau tidaknya sebuah kebijakan. Sarana dan prasarana di kantor Satpol PP sendiri sepertinya masih kurang maksimal. Selain Petugas Internal (PTI) tentunya sarana kelengkapan kamera pengawas CCTV penting adanya untuk memaksimalkan pengawasan disana selama 24 jam.

\section{Tidak Tegasnya Pemberlakuan Sanksi}

Sanksi merupakan suatu akibat yang didapatkan oleh jika orang tersebut melakukan pelanggaran terhadap sebuah peraturan. Tanpa adanya saksi bagi pelanggar sudah bisa ditebak bahwa sehebat apapun itu peraturan akan sia - sia jika tidak dipatuhi.

\section{Kurangnya Motivasi Personel Satpol PP Kota Palangka Raya Mempelajari Perda - Perda dan Peraturan Lainnya Yang Berlaku di Kota Palangka Raya}

Selain mengharapkan adanya sosialisasi tentang pemberlakuan peraturan 
daerah tentunya sudah menjadi kewajiban personel Satpol PP adalah mempelajari secara mandiri semua perda dan peraturan sejenis lainnya yang berlaku diwilayah hukum mereka.

\section{Masih Adanya SPG - SPG yang Bebas Mempromosikan Produk Rokok di Kantor Satpol PP Kota Palangka Raya \\ Selama kegiatan penelitian} berlangsung di Satpol PP Kota Palangka Raya ditemukan fakta bahwa masih ditemukan adanya sales promotion girl (SPG) yang bebas mempromosikan produk rokok di Kantor Satpol PP Kota Palangka Raya.

\section{KESIMPULAN}

Berdasarkan hasil penelitian dan pembahasan serta didukung oleh data-data yang telah dikumpulkan selama penelitian dapat diambil kesimpulan bahwa :

Peraturan Daerah Nomor 3 Tahun 2014 Tentang Kawasan Tanpa Rokok (KTR) di Satpol PP Kota Palangka Raya belum diimplementasikan dengan baik.

Beberapa upaya yang bisa dilakukan untuk mengoptimalkan implementasi peraturan daerah no.3 tahun 2014 Tentang Kawasan Tanpa Rokok (KTR) agar dapat diimplementasikan dengan baik di Kantor Satuan Polisi Pamong Praja Kota Palangka Raya antara lain : a. Harus adanya sosialisasi secara terstruktur dan sistematis, b. Ketika ada personel Satpol PP Kota Palangka Raya yang melanggar merokok di Kawasan Tanpa Rokok maka Pimpinan dan Petugas Tindak Internal (PTI) harus berani memberikan sanksi yang tegas, c. Pimpinan, Unsur Pimpinan, PTI harus benar benar berkomitmen untuk tidak merokok di Kawasan Tanpa Rokok, d. Harus adanya larangan keras bagi SPG - SPG khususnya SPG Rokok untuk tidak bebas berjualan, mempromosikan dan mengiklankan rokok di Kantor Satpol PP Kota Palangka Raya. e. Harus ada penambahan kamera pemantau/CCTV, f. Harus ada Sistem Operasional Prosedur (SOP) yang jelas bagi Petugas Tindak Internal ( PTI) dalam hal ini yaitu SOP yang sistematis bagaimana PTI melakukan Pengawasan dan Penegakan Perda.

\section{DAFTAR PUSTAKA}

Agustino, Leo. 2014. Dasar - dasar Kebijakan Publik. Bandung : Alfabeta.

Alwi, Hasan. 2007. Kamus Besar

Bahasa Indonesia. Jakarta: Balai

Pustaka

Dunn, William N. 2003. Pengantar Analisis Kebijakan Publik. Yogyakarta:
GadjahMada University Press.

Hasan, Ibnu. 2000. Metode Penelitian Sosial. Jakarta : Pustaka Sinar Harapan. Hazim, Nur Kholif. 2004. Kamus Lengkap Bahas Indonesia "super baru"

Surabaya : TerbitTerang.

Herujito. 2006. Dasar-Dasar Manajemen. Jakarta : Grasindo.

Idrus, Muhammad. 2009. Metode Penelitian Ilmu Sosial Pendekatan Kualitatif dan Kuantitatif. Jakarta : Erlangga.

Maleong, Lexy. 2007. Metodologi Penelitian Kualitatif. Bandung : PT.Remaja.

Mangkunegara, Anwar Prabu. 2008. Perilaku dan Budaya Organisasi,. Bandung Rafika Adi Tama Bandung.

Manulang, M. 1995. Dasar - Dasar Manajemen. Jakarta : Ghalia Indonesia. Muhadjir, Noeng. 2000. Metode Penelitian Kualitatif. Yogyakarta : Rake Sarasih Pasolong, Harbani . 2007. Teori Administrasi Publik. Bandung: Alfabeta. Prayudi. 198I. Hukum Administrasi Negara. Jakarta : Ghalia Indonesia.

Purwanto, Erwan Agus, dkk. 2015.

Implementasi Kebijakan Publik "Konsep dan Aplikasinya di Indonesia”. Yogyakarta : Gava Media.

Ramasya, Adi. 20I0. Kebijakan Politik Untuk Indonesia Masa Kini. Bandung : Dieva Sanjaya.

Santosa, Panji. 2008. Administrasi Publik "Teori dan Aplikasi Good Governance"'. Bandung : Refika Aditama.

Setiawan, Guntur. 2004. Implementasi Dalam Birokrasi Pembangunan. Bandung Remaja Rosdakarya.

Sinambela, Lijan Poltak. 200I. Reformasi Pelayanan Publik "Teori, Kebijakan Dan Implemetasi. Jakarta : PT.BumiAksara. 
Soekanto, Soerjono. 1983. Faktor - Faktor Yang Mempengaruhi Penegakan Hukum. Jakarta : UI Press.

Sugiyono.2007. Metode Penelitian Kuantitatif dan Kualitatif dan $R$ \& $D$. Bandung : Alfabeta.

Tangkilisan, Hessel Nogi S. 2002. Kebijakan dan Managemen Otonomi Daerah. Yogyakarta : Lukman Offset.

Tanjung, Nur Bahdin. 2005. Pedoman Penulisan Karya Ilmiah. Jakarta : Kencana Predana Media Group.
Thoha, Miftah. 2008. Ilmu Administrasi Publik Kontemporer. Jakarta : Kencana Media Grup.

Usman, Nurdin. 2002. Konteks Implementasi Berbasis Kurikulum. Jakarta : PT.Raja Grafindo Persada.

Winarno, Budi. 2002. Teori dan Proses Kebijakan Publik. Yogyakarta : Pressindo 20I4. Kebijakan Publik "Teori, Proses dan Studi Kasus". Yogyakarta : CAPS (Center of Academic Publishing Service). 